\title{
Microsatellite Markers for Genes Lr34/Yr18 and Other Quantitative Trait Loci for Leaf Rust and Stripe Rust Resistance in Bread Wheat
}

\author{
K. Suenaga, R. P. Singh, J. Huerta-Espino, and H. M. William
}

First, second, and fourth authors: International Maize and Wheat Improvement Center (CIMMYT), Apdo. Postal 6-641, 06600, Mexico, D.F., Mexico; and third author: Campo Experimental Valle de Mexico-INIFAP, Apdo. Postal 10, 56230, Chapingo, Edo. de Mexico, Mexico.

Current address of K. Suenaga: Japan International Research Center for Agricultural Sciences (JIRCAS), 1-1 Ohwashi, Tsukuba, Ibaraki 305-8686, Japan.

Accepted for publication 27 January 2003.

\begin{abstract}
Suenaga, K., Singh, R. P., Huerta-Espino, J., and William, H. M. 2003. Microsatellite markers for genes $\operatorname{Lr} 34 / \mathrm{Yr} 18$ and other quantitative trait loci for leaf rust and stripe rust resistance in bread wheat. Phytopathology 93:881-890.

Leaf rust and stripe rust, caused by Puccinia triticina and $P$. striiformis, respectively, are important diseases of wheat in many countries. In this study we sought to identify molecular markers for adult plant resistance genes that could aid in incorporating such durable resistance into wheat. We used a doubled haploid population from a Japanese cv. Fukuho-komugi $\times$ Israeli wheat Oligoculm cross that had segregated for resistance to leaf rust and stripe rust in field trials. Joint and/or singleyear analyses by composite interval mapping identified two quantitative trait loci (QTL) that reduced leaf rust severity and up to 11 and 7 QTLs

type. Except for a QTL on chromosome 7DS, no common QTL for leaf rust and stripe rust was detected. QTL-7DS derived from 'Fukuhokomugi' had the largest effect on both leaf rust and stripe rust severities, possibly due to linked resistance genes $\operatorname{Lr} 34 / \mathrm{Yr} 18$. The microsatellite locus Xgwm295.1, located almost at the peak of the likelihood ratio contours for both leaf and stripe rust severity, was closest to $\operatorname{Lr} 34 / \mathrm{Yr} 18$. QTLs located on 1BL for leaf rust severity and 3BS for stripe rust infection type were derived from 'Oligoculm' and considered to be due to genes $L r 46$ and $Y r 30$, respectively. Most of the remaining QTLs for stripe rust severity or infection type had smaller effects. Our results indicate there is significant diversity for genes that have minor effects on stripe rust resistance, and that successful detection of these QTLs by molecular markers should be helpful both for characterizing wheat genotypes effectively and combining such resistance genes.
\end{abstract} that might have influenced stripe rust severity and infection type, respectively. Four common QTLs reduced stripe rust severity and infection
Additional keywords: slow rusting, Triticum aestivum.
Leaf (brown) rust and stripe (yellow) rust, caused by Puccinia triticina Eriks. and P. striiformis Westend., respectively, are the most common fungal diseases of wheat in many countries. Several genes that confer resistance to these rusts have been identified and used in breeding programs to reduce grain yield losses (19). A majority of these designated resistance genes are race-specific and have become ineffective in combating current pathogen populations. In contrast, slow rusting (6) resistance, which expresses at the adult plant stage, is quantitatively inherited and based on genes that have minor to intermediate but additive effects $(3,13$, $22,25,40)$. Because it is often durable, such resistance should be of primary interest to most wheat breeders around the world $(12,40)$.

Molecular markers, viz. random amplified polymorphic DNA (RAPD), restriction fragment length polymorphism (RFLP), and microsatellite (SSR) markers linked to race-specific rust resistance genes have been identified in wheat and can be used in markerassisted selection. Three RAPD and one RFLP markers showed complete linkage to leaf rust resistance gene $\operatorname{Lr} 9$ (34). Robert et al. (31) identified one RAPD and one RFLP marker that are closely linked to the stripe rust resistance gene $\mathrm{Yr} 17$. More recenly, SSR markers have been developed $(27,32,45,46)$ and utilized for tagging rust resistance genes such as Lr39 (29) and YrH52 (26).

Genes Lr34 and Yrl8 confer slow rusting resistance to leaf and stripe rust, respectively, and are known to be pleiotropic or completely linked to each other $(18,37)$. Although genes $\operatorname{Lr} 34$ and

Corresponding author: K. Suenaga; E-mail address: suenagak@affrc.go.jp

Publication no. P-2003-0513-02R

(c) 2003 The American Phytopathological Society
Yr18 may not provide adequate resistance under high disease pressure when present alone $(16,38,39)$, they could contribute to achieving acceptable levels of resistance in combination with other slow rusting genes (40,44). Genes Lr34 and Yr18 have been used extensively in the International Maize and Wheat Improvement Center (CIMMYT) wheat breeding program and elsewhere $(19,40)$. Leaf tip necrosis $(L t n)$, a morphological trait, shows complete linkage or pleiotropism with $\operatorname{Lr34}$ and $\operatorname{Yr} 18$ (36) and could be used in some environments as a marker to identify wheat lines carrying these genes. Since slow rusting resistance is quantitatively inherited, quantitative trait loci (QTL) analysis has been applied to map genes conferring it. Lr34/Yr18 and other resistance genes effective at the adult plant stage have been mapped by QTL analysis using molecular markers $(2,5,21,23,24,42)$.

A doubled haploid (DH) population developed from a cross between the Japanese wheat 'Fukoho-komugi' and the Israeli wheat 'Oligoculm' showed transgressive segregations for leaf rust and stripe rust resistance in field trials. The objective of our study was to identify the QTLs that confer resistance to leaf and stripe rusts in that population.

\section{MATERIALS AND METHODS}

Plant materials. The doubled haploid population used in our study was developed from a cross between Japanese wheat 'Fukuho-komugi' and Israeli wheat 'Oligoculm' by means of wheat $\times$ maize crosses (47). This population, consisting of 107 DH lines, had been used before to construct a partial genetic map using RAPDs (1) and a full map with RAPD, RFLP, and SSR markers (manuscript in preparation). 'Fukuho-komugi' displayed 
leaf tip necrosis in field trials in Mexico and hence, is considered to possess $\operatorname{Lr} 34 / \mathrm{Yr} 18(9,36)$.

Genotyping by molecular markers. RAPD, RFLP, and SSR markers were used to construct a "framework" map for QTL analysis. The population was grown in the greenhouse at CIMMYT to harvest leaf tissue for DNA extraction. Genomic DNA was extracted from lyophilized leaf tissue using an alkyltrimethylammonium bromide-based extraction procedure. DraI, EcoRI, EcoRV, HindIII, and XbaI were used for restriction digestion. DNA extraction, restriction digestion, and Southern hybridization were conducted following protocols described by Hoisington et al. (10). One hundred and eighty RFLP probes were used for parental screening using a nonradioactive chemiluminescent technique (10). Forty-seven probes were chosen and further used for genotyping the population. RFLP probes were provided by M. E. Sorrells, Cornell University, (bcd, cdo, and wg); K. Tsunewaki, Kyoto University, Japan (Tag); M. Gale, John Innes Centre, UK
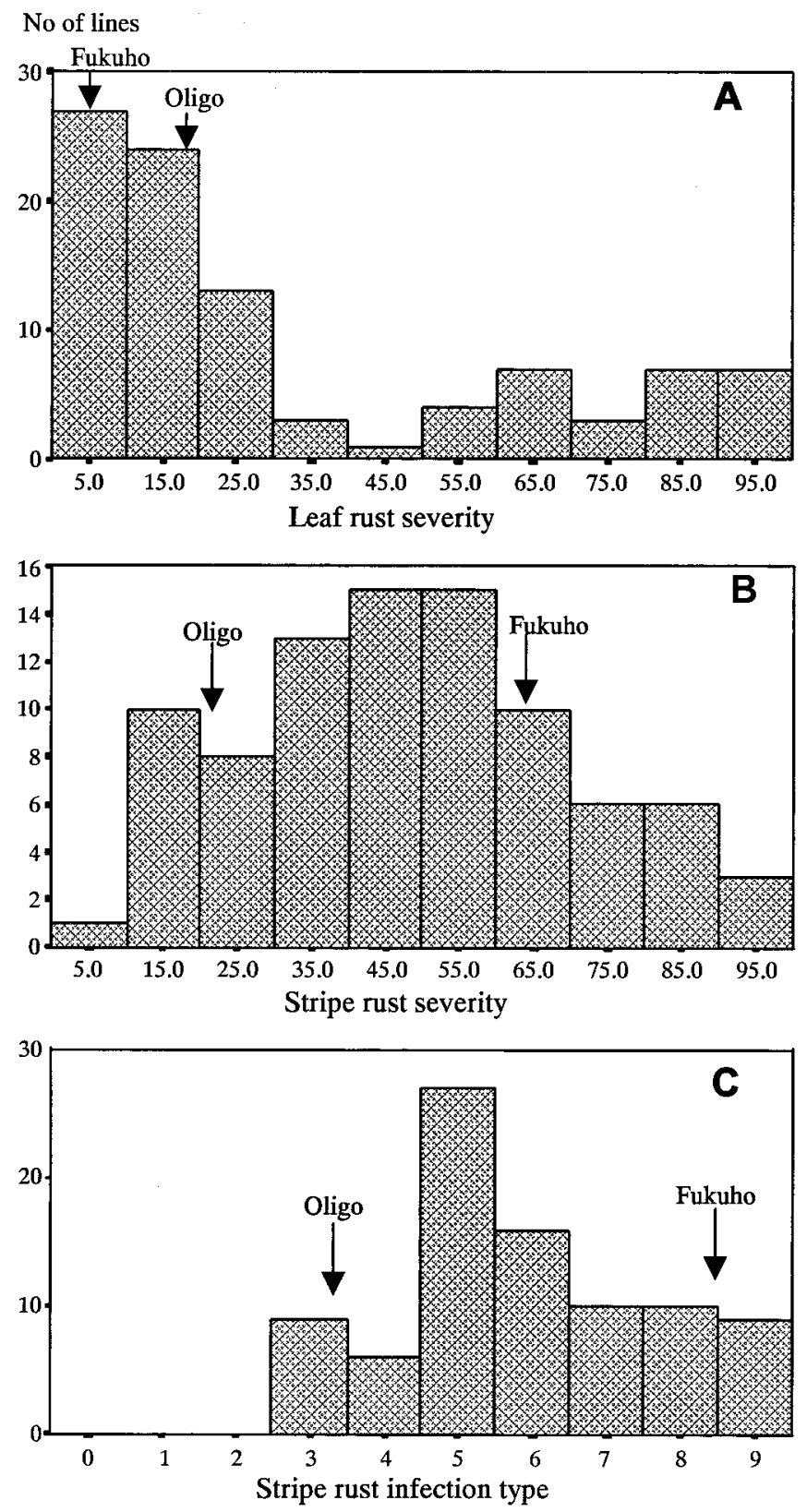

Fig. 1. Frequency distribution of 'Fukuho-komugi' $\times$ 'Oligoculm' doubled haploid lines for: A, leaf rust severity (mean for 2 years), B, stripe rust severity ( 3 years in Mexico), and $\mathbf{C}$, stripe rust infection type (3 years). Mean values for the parents 'Fukuho-komugi' (Fukuho) and 'Oligoculm' (Oligo) are indicated by arrows. (psr); P. Leroy, National Institute of Agricultural Research, France (fba and fbb); and B. S. Gill, Kansas State University, (ksu).

The same genomic DNA was used for microsatellite analysis. Procedures for polymerase chain reaction (PCR) followed the method of Hoisington et al. (10). PCR amplification was performed using a "touchdown" (7) program to reduce the nonspecific amplification products. Initial annealing temperature was $64^{\circ} \mathrm{C}$ and decreased $1{ }^{\circ} \mathrm{C}$ per cycle for seven cycles. The reaction was repeated 35 times at $57^{\circ} \mathrm{C}$. Depending on the microsatellite primers used in amplification, initial temperature was increased or decreased by $5^{\circ} \mathrm{C}$ to obtain discrete amplification products. PCR products were separated using both nondenaturing and denaturing acrylamide gels (14 cm wide $\times 12 \mathrm{~cm}$ long $\times 1 \mathrm{~mm}$ thick). Gels were stained according to Sanguinetti et al. (33). Six hundred and seventy SSR primers were used for parental screening, and 400 of those were selected for genotyping the population. Microsatellites used in this study were: WMC (Wheat Microsatellite Consortium, P. Isaac, Agrogene, France); GWM (32); GDM (27); PSP (46); and those from Cornell University (15). Aliquots of PSP primers were provided by M. Gale, John Innes Centre, UK under a material transfer agreement. The sequences of some GWM primers, which have not been published, and GDM primers (27) were also obtained under a material transfer agreement from M. S. Röder, Institute for Plant Genetics and Crop Research, Germany.

Disease screening. Nonreplicated field trials for disease screening were conducted during the 1999 to 2000 and 2000 to 2001 crop seasons at CIMMYT's research station in Ciudad Obregon, Sonora State, Mexico, for leaf rust; and during the 1999, 2000, and 2001 crop seasons at CIMMYT's research station in Toluca in the central highlands of Mexico, for stripe rust severity and infection type. Three-gram seeds (approximately 60 plants) of

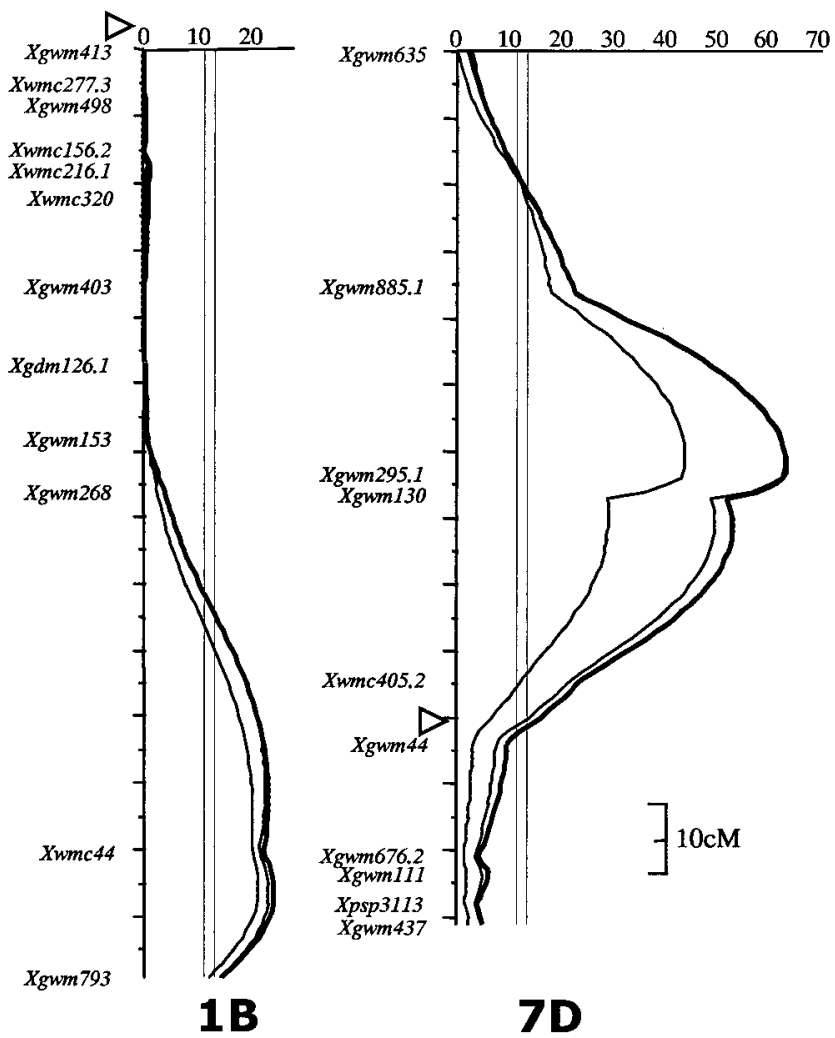

Fig. 2. Likelihood ratio (LR) contours obtained by composite interval mapping for two quantitative trait loci mapped on chromosomes 1BL and 7DS that reduced leaf rust severity in 'Fukuho-komugi' $\times$ 'Oligoculm' doubled haploid population. Bold contour indicates LR by joint analysis with 2000 and 2001 data. LR thresholds, equivalent to LOD $=2.5$ are 11.5 for single year and 13.8 for joint analysis. Short arms are toward the top and the open arrow indicates centromere. 
each DH line, the parents, and the susceptible check cv. Avocet S were planted in two-paired 1-m rows, $20 \mathrm{~cm}$ apart, on top of raised beds $75 \mathrm{~cm}$ wide. Epidemics of leaf and stripe rusts were initiated approximately 6 weeks after planting in Ciudad Obregon and 4 weeks after planting in Toluca. The highly susceptible spreader $\mathrm{cv}$. Morocco was hill-planted in the middle of a $0.5-\mathrm{m}$ pathway on one side of each plot and sprayed with a suspension of urediniospores in a lightweight mineral oil (Soltrol 170; Phillips 66 Co., Bartlesville, OK). The Mexican P. triticina race MCJ/SP, nomenclature based on Singh (35), used in all studies has the avirulence/ virulence formula $\operatorname{Lr} 2 a, 2 b, 2 c, 3 k a, 9,16,19,21,24,25,28,29,30,32$,$33 / 1,(3), 3 b g, 10,11,12,13,14 a, 14 b, 15,17,18,20,22 b, 23,26,27+31$. The $P$. striiformis culture Mex96.11 used in all studies has the avirulence/virulence formula $\operatorname{Yr} 1,4,5,8,10,15,17,24, \mathrm{Sp} / 2,3,6,7,9,27, A$. Fresh inoculum obtained by multiplying urediniospores on susceptible 'Morocco' in the greenhouse was used in all inoculations.

Rust severity in the form of percentage of infected leaf area, based on the modified Cobb scale (28), was recorded on flag leaves approximately 100 days after planting in Ciudad Obregon and 70 days after planting in Toluca. Infection type on flag leaves based on the 0 to 9 scale (20) was also recorded for stripe rust. Stripe rust severity was scored twice in 1999 (once on 27 July and once on 5 August).

Stripe rust severity data were also available from the Plant Breeding Institute, University of Sydney, Cobbitty, Australia, from evaluations carried out by the first author in 1995. Each DH line was hill-planted with $20 \mathrm{~cm}$ between hills and $70 \mathrm{~cm}$ between rows. The rust epidemic was initiated by spraying the plots with $P$. striiformis race 110 E143 A+ (48) suspended in lightweight mineral oil. Rust severity was scored twice after heading at 14-day interval, and the mean value was used for analysis.

Because the population segregated for facultative or wintergrowth habits, data on 96 lines grown in Ciudad Obregon and 87 lines in Toluca were used for analysis. DH lines were also classified for the presence and absence of leaf tip necrosis in the second year of testing in Ciudad Obregon.

Map construction and QTL detection. MAPMAKER (14) was used to analyze 598 markers and to create a framework map with 343 markers for QTL detection. QTLs were identified using a software program for composite interval mapping (CIM), developed by C. Jiang at CIMMYT in $1996(11,50)$. Ribaut et al. (30) have summarized the procedure for QTL detection using this program. QTL analysis was performed jointly using all data sets for each trait (joint analysis) and then separately using a single data set (single-year/environment analysis). QTLs were considered to have a significant effect when likelihood ratio (LR) statistics exceeded a threshold equivalent to 2.5 as logarithm of odds (LOD) score.

\section{RESULTS}

Phenotypic correlation between data. Leaf rust severity data for the DH lines recorded in 2 years were highly correlated $(r=$
0.92, $P<0.01)$. Similarly, stripe rust infection types of the DH lines recorded over 3 years also showed high and significant $(P<$ 0.01) $r$ values ranging between 0.79 and 0.92 . Stripe rust severity recorded in Australia showed $r$ values between 0.72 and 0.81 with the four data sets from Mexico, whereas $r$ values for Mexican data sets ranged between 0.79 and 0.87 .

Because of the high correlation coefficient, mean leaf rust severity, stripe rust infection type, and severity data were used for determining the relationship among the three traits. Highly significant $(P<0.01) r$ values $(0.43$ between leaf rust severity and stripe rust infection type, 0.58 between leaf rust severity and stripe rust severity, and 0.79 between stripe rust infection type and severity) indicated that at least some genes were common to the three traits.

Phenotypic distribution. Some DH lines and the susceptible check 'Avocet S' displayed approximately 80 to $100 \%$ mean leaf rust severity in field trials, while the two parents, 'Fukuhokomugi' and 'Oligoculm', on average showed 5.0 and $17.5 \%$ severity, respectively. The population exhibited transgressive segregation with a wide range of variation including high susceptibility; the distribution was skewed towards genotypes showing lower severities (Fig. 1A). When lines showing severities of $80 \%$ and above (similar to the susceptible check 'Avocet $S$ ') were considered susceptible, then the distribution of $82 \mathrm{R}$ and $14 \mathrm{~S}$ lines was in accordance to a 7:1 ratio $\left(\chi_{7 \mathrm{R}: 1 \mathrm{~S}}^{2}=0.4, P>0.5\right)$, expected for segregation of three independent resistance genes. The 7:1 segregation ratio indicates that three resistance genes segregated in this cross and that each parent possesses at least one adult plant resistance gene for leaf rust. Since 'Fukuho-komugi' showed leaf tip necrosis in the field, this cultivar is thought to have Lr34/Yrl8 (18,36,37). Both parents displayed susceptible infection types indicating that the genes involved in resistance were of "slow rusting" (6) nature.

'Oligoculm' showed a higher level of stripe rust resistance (both severity and infection type) than 'Fukuho-komugi'. The mean stripe rust severity and infection type of 'Oligoculm' were $22.7 \%$ and 3.3, respectively, whereas those for 'Fukuho-komugi' were $64.3 \%$ and 8.5 (Fig. 1B and C). The population exhibited continuous variation similar to a normal distribution for both severity and infection type indicating that several minor genes may be involved in stripe rust resistance. Segregation of fully susceptible genotypes indicated that the parents possessed different resistance genes for severity and for infection type. If three of the $87 \mathrm{DH}$ lines showing 95\% stripe rust severity on average (Fig. 1B) are considered completely susceptible, it would appear that five independent genes conferred resistance leading to a reduction in stripe rust severity $\left(\chi_{31 \mathrm{R}: 1 \mathrm{~S}}^{2}=0.03, P>0.9\right)$. Mean infection type of nine of the $87 \mathrm{DH}$ lines was recorded as 9 on the 0 to 9 scale (Fig. 1C) indicating that a minimum of three genes reduced infection type $\left(\chi_{7 \mathrm{R}: 1 \mathrm{~S}}^{2}=0.4, P>0.5\right)$.

QTL analysis for leaf rust severity. Joint analysis with a CIM program using combined leaf rust severity data for 2 years detected two QTLs on chromosome arms 7DS and 1BL with

TABLE 1. Effects of quantitative trait loci (QTLs) that reduce leaf rust severity in 'Fukuho-komugi' $\times$ 'Oligoculm' doubled haploid (DH) population detected by composite interval mapping (CIM) using 2 years of data from field trials and jointly analyzed using the CIM program

\begin{tabular}{|c|c|c|c|c|c|c|c|}
\hline \multirow[b]{2}{*}{ Chromosome } & \multirow[b]{2}{*}{ Marker locus ${ }^{\mathrm{u}}$} & \multirow[b]{2}{*}{$\mathrm{LR}^{\mathrm{v}}$} & \multicolumn{2}{|c|}{2000} & \multicolumn{2}{|c|}{2001} & \multirow[b]{2}{*}{ Resistance from ${ }^{y}$} \\
\hline & & & $R^{2 \mathrm{w}}$ & $\operatorname{Add}^{\mathrm{x}}$ & $R^{2}$ & Add & \\
\hline $1 \mathrm{BLD}^{\mathrm{z}}$ & Xwmc44 & 25.03 & 12.9 & 12.80 & 17.4 & 12.30 & Oligo \\
\hline 7DS & Xgwm295.1 & 64.22 & 45.2 & 21.70 & 36.4 & 17.30 & Fukuho \\
\hline
\end{tabular}

u Marker nearest to the peak of likelihood ratio plot.

${ }^{v}$ Likelihood ratio (LR); thresholds equivalent to LOD $=2.5$ are 11.5 for single year and 13.8 for joint analysis.

${ }^{w}$ The percentage of phenotypic variation explained by each QTL.

$x$ Additive effect.

y Fukuho = 'Fukuho-komugi'; Oligo = 'Oligoculm'.

${ }^{\mathrm{z}} \mathrm{D}=$ distal region of the chromosome. 
highly significant LR (Fig. 2). Single-year analysis also identified QTLs in the same regions. The effects of the locus on 7DS designated as QTL-7DS were higher than those by QTL-1BL. The percentage of total variation explained by QTL-7DS $\left(\% R^{2}\right)$ was $45.2 \%$ in 2000 and $36.4 \%$ in 2001 (Table 1). 'Fukuho-komugi', which displays leaf tip necrosis, showed association with resistance at this QTL. SSR markers Xgwm295.1 and Xgwm130 flanked the QTL-7DS region. Ltn could not be mapped into a unique position with a threshold of $\mathrm{LOD}=2.0$. The most likely position of Ltn was $6.3 \mathrm{cM}$ distal to Xgwm295.1. QTL-1BL explained approximately $12.9 \%$ of total variation in 2000 and $17.4 \%$ in 2001. 'Oligoculm' contributed resistance associated with chromosome 1BL. The location of QTL-7DS and QTL-1BL indicated that these QTLs could be due to the effects of resistance genes Lr34 and Lr46, known to be located in these regions $(8,23,41)$.

QTL analysis for stripe rust severity. Five data sets were available for stripe rust severity. Joint analysis detected seven significant QTLs using the five data sets (Fig. 3). The QTL on 7DS showed the largest effect $\left(\% R^{2}=11\right.$ to $24 \%$; Table 2$)$ and was considered to be due to gene $\operatorname{Yr} 18$, known to be located in the same region (42). This resistance originated from 'Fukuhokomugi', whereas all other resistance QTLs were derived from 'Oligoculm'. Except for some cases, viz. QTL-4B in Australia and QTL-6B in Toluca (detected in 1999 and 2001), LR contours for other QTLs in each year were similar to contours
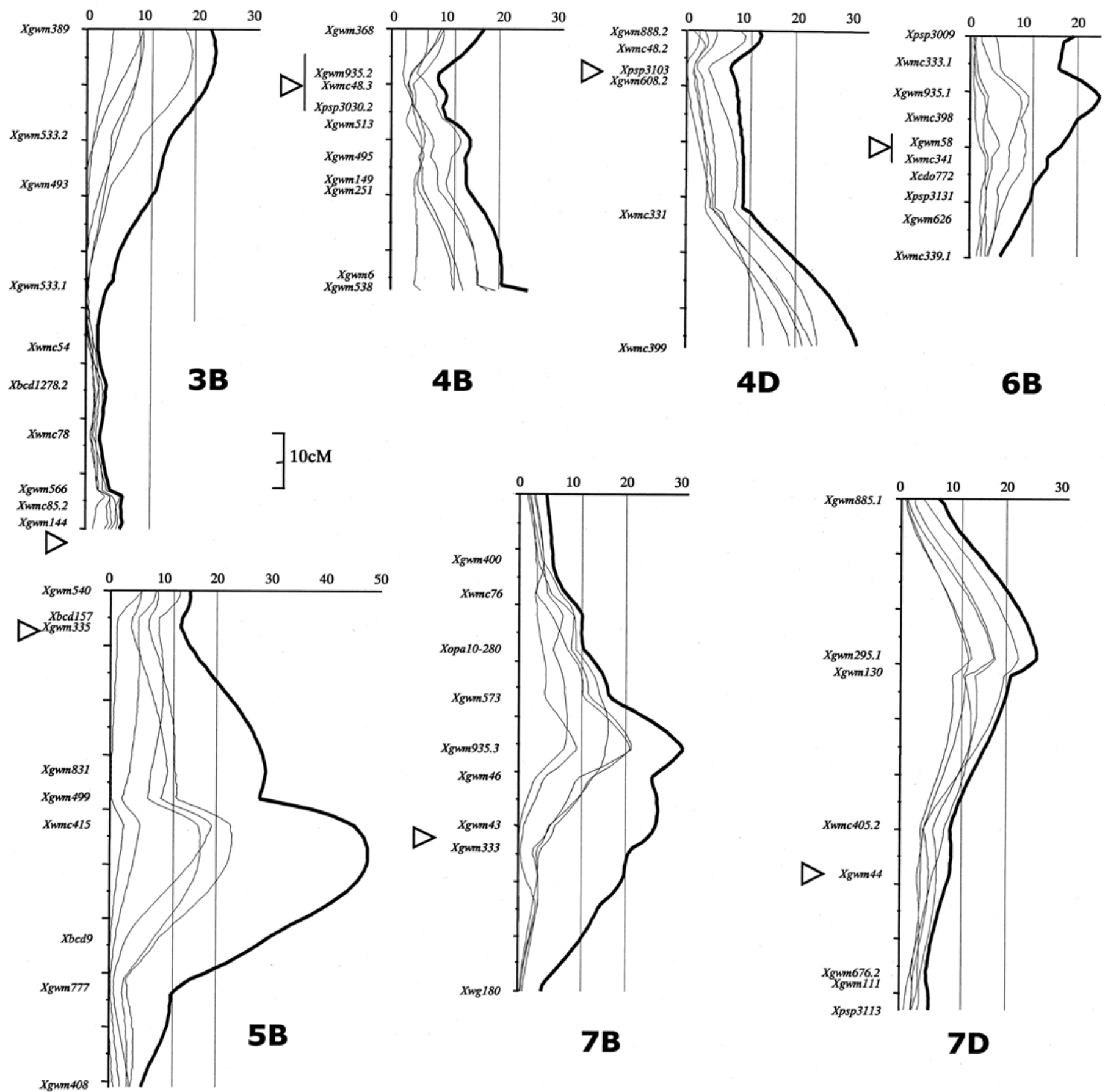

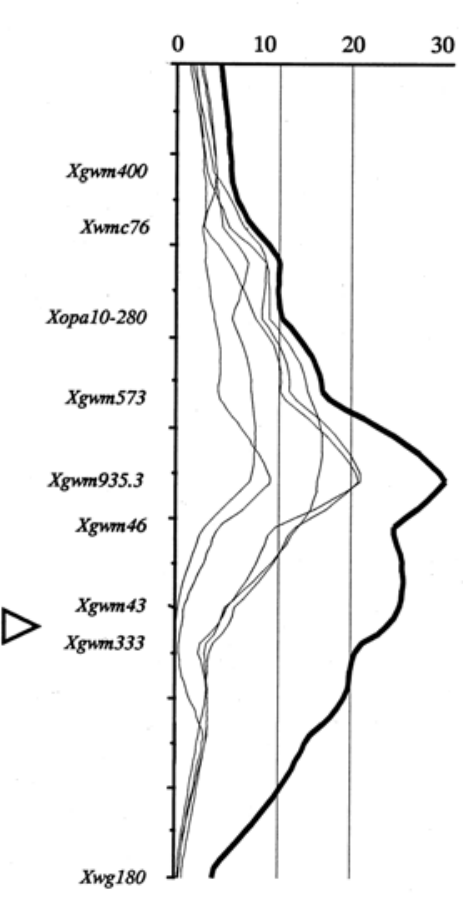

7B

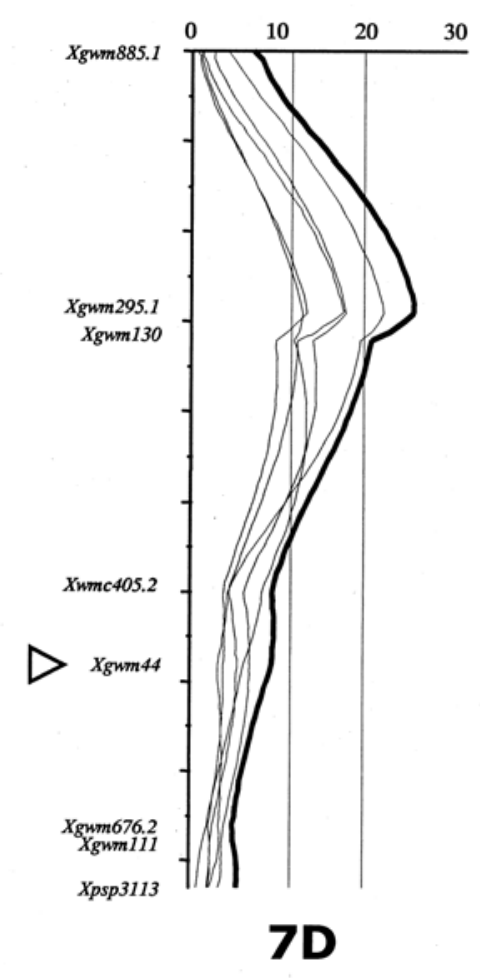

Fig. 3. Likelihood ration (LR) contours obtained by composite interval mapping for seven quantitative trait loci mapped on chromosomes 3BS, 4BL, 4DL, 5BL, 6BS, 7BS, and 7DS that reduce stripe rust severity in 'Fukuho-komugi' $\times$ 'Oligoculm' doubled haploid population. Bold contours indicate LR by joint analysis with data from five environments. LR thresholds, equivalent to LOD $=2.5$ are 11.5 for single environment and 19.7 for joint analysis. Short arms are toward the top and the open arrow indicates centromere. 
obtained from joint analysis (Fig. 3). Four additional QTLs could be detected when single-environment analyses were conducted (Table 2).

QTL analysis for stripe rust infection type. Four QTLs were detected on chromosomes 2DL, 3BS, 5BL, and 7BL by joint analysis combining three sets of data from 1999 to 2001 (Table 3; Fig. 4). Although peak LR values for QTL-2DL, QTL-5BL, and QTL-7BL were slightly lower than the threshold value (15.9, equivalent to $\mathrm{LOD}=2.5$ ), LR contours for the 3 years analyzed by single year showed peaks in the region similar to that observed by joint analysis (Fig. 4). Therefore, the three regions were considered to contain putative QTLs that reduced stripe rust infection type. Single-year analysis detected three additional QTLs on chromosomes 2BL and 4DL, and in 7DS centromeric region (Table 3). QTL-3BS had the largest effect, explained 15.1 to $24.5 \%$ of total variation, and was considered to be due to the effects of Yr30 $(40,42)$. The other three QTLs, as well as those detected by singleyear analysis, exhibited lower levels of contribution and a $\% R^{2}$ ranging from 2.5 to $12.7 \%$. Of the seven putative QTLs detected for infection type, the three that were detected by joint analysis and one by single-year analysis were the same as QTLs detected for stripe rust severity.

Genotypic effects of marker loci on leaf and stripe rusts. Table 4 shows the genotypic effects of marker loci flanking the detected QTLs. Except for Xwmc44 on 1BL and Xgwm295.1 on 7DS, no clear association between leaf and stripe rust resistance was found. Association between leaf and stripe rust severity detected by the marker Xwmc405.2 is considered to be due to the linkage of approximately $30 \mathrm{cM}$ between Xgwm295.1 and $X w m c 405.2$. However, several loci tended to affect both stripe rust severity and infection type. This was typically shown for Xgwm349 on 2DL, Xgwm389 on 3BS, Xwmc399 on 4DL, and Xwmc415 on 5BL.

Although we had difficulty classifying DH lines for Ltn probably due to large variation in agronomic traits such as maturity, Ltn showed a strong association with Xgwm295.1. The mean differences in leaf and stripe rust severity by Ltn genotype were 46.6 and $20.8 \%$, respectively, whereas those by Xgwm295.1 (chromosome $7 \mathrm{DS}$ ) were 40.1 and $18.8 \%$. The difference in leaf rust severity by Xwmc44 (chromosome 1BL) was $25.5 \%$. Genotypic

TABLE 2. Effects of quantitative trait loci (QTLs) that reduce stripe rust severity in 'Fukuho-komugi' $\times$ 'Oligoculm' doubled haploid (DH) population detected by composite interval mapping using five data sets from field trials

\begin{tabular}{|c|c|c|c|c|c|c|c|c|c|c|c|c|c|}
\hline \multirow[b]{2}{*}{ Chromosome } & \multirow[b]{2}{*}{ Marker locus ${ }^{\mathrm{s}}$} & \multirow[b]{2}{*}{$\mathrm{LR}^{\mathrm{t}}$} & \multicolumn{2}{|c|}{ Australia } & \multicolumn{2}{|c|}{ July 1999} & \multicolumn{2}{|c|}{ August 1999} & \multicolumn{2}{|c|}{2000} & \multicolumn{2}{|c|}{2001} & \multirow[b]{2}{*}{ Resistance from ${ }^{\star}$} \\
\hline & & & $R^{2 \mathrm{u}}$ & $\operatorname{Add}^{v}$ & $R^{2}$ & Add & $R^{2}$ & Add & $R^{2}$ & Add & $R^{2}$ & Add & \\
\hline \multicolumn{14}{|l|}{ Joint analysis ${ }^{x}$} \\
\hline $3 \mathrm{BS}$ & Xgwm389 & 23.16 & 3.1 & 6.8 & 2.9 & 5.7 & 3.4 & 7.0 & 4.9 & 10.3 & 0.2 & 4.6 & Oligo \\
\hline $4 \mathrm{BL}$ & Xgwm538 & 24.68 & 1.8 & 4.9 & 11.2 & 6.9 & 4.4 & 6.8 & 7.3 & 7.7 & 12.3 & 8.6 & Oligo \\
\hline 4DL & Xwmc399 & 31.96 & 8.0 & 11.0 & 5.7 & 7.9 & 6.0 & 8.9 & 6.1 & 10.9 & 2.5 & 7.4 & Oligo \\
\hline $5 \mathrm{BL}$ & $X w m c 415$ & 47.81 & 16.1 & 12.1 & 2.4 & 4.0 & 8.0 & 9.9 & 6.3 & 10.1 & 2.5 & 3.3 & Oligo \\
\hline $6 \mathrm{BSC}^{\mathrm{y}}$ & Xgwm 935.1 & 23.00 & 3.8 & 6.8 & 0.6 & 0.9 & 0.9 & 3.5 & 3.5 & 7.2 & 0.5 & 3.0 & Oligo \\
\hline $7 \mathrm{BS}$ & Xgwm 935.3 & 30.29 & 4.1 & 6.5 & 1.0 & 4.6 & 3.8 & 9.5 & 1.6 & 8.5 & 5.2 & 8.9 & Oligo \\
\hline 7DS & Xgwm295.1 & 25.28 & 17.1 & 9.3 & 12.4 & 5.7 & 12.2 & 8.6 & 10.7 & 7.8 & 23.7 & 9.5 & Fukuho \\
\hline Total $R^{2}$ by joi & nalysis & & 51.7 & & 41.1 & & 42.3 & & 46.0 & & 52.5 & & \\
\hline \multicolumn{14}{|c|}{ Single environment analysis ${ }^{z}$} \\
\hline 1BLC & Xwmc320 & - & - & - & - & - & - & - & - & - & 10.4 & 8.0 & Fukuho \\
\hline 2DS & $X g w m 261$ & - & - & - & 5.7 & 5.3 & 5.4 & 6.9 & - & - & - & - & Oligo \\
\hline 2DL & Xgwm349 & - & - & - & 10.1 & 5.6 & 11.4 & 8.9 & - & - & - & - & Fukuho \\
\hline $5 \mathrm{DL}$ & Xwmc215 & - & - & - & 3.9 & 5.9 & - & - & - & - & - & - & Oligo \\
\hline
\end{tabular}

s Marker nearest to the peak of likelihood ratio plot.

${ }^{t}$ Likelihood ratio (LR); thresholds equivalent to LOD $=2.5$ are 11.5 for single environment and 19.7 for joint analysis.

u The percentage phenotypic variation explained by each QTL.

$\checkmark$ Additive effect.

${ }^{\mathrm{w}}$ Fukuho $=$ 'Fukuho-komugi'; Oligo = 'Oligoculm'

${ }^{x}$ Five data sets from Cobbitty, Australia (1995) and Toluca, Mexico (July 1999, August 1999, 2000, and 2001) were jointly analyzed.

${ }^{y} \mathrm{C}=$ the region near the centromere.

z Analyzed by individual data set. Common QTLs from joint analysis not included.

TABLE 3. Effects of quantitative trait loci (QTLs) that reduce stripe rust infection type in 'Fukuho-komugi' $\times$ 'Oligoculm' doubled haploid (DH) population detected by composite interval mapping using 3 years of data from field trials

\begin{tabular}{|c|c|c|c|c|c|c|c|c|c|}
\hline \multirow[b]{2}{*}{ Chromosome } & \multirow[b]{2}{*}{ Marker locus $^{\mathrm{s}}$} & \multirow[b]{2}{*}{$\mathrm{LR}^{\mathrm{t}}$} & \multicolumn{2}{|c|}{1999} & \multicolumn{2}{|c|}{2000} & \multicolumn{2}{|c|}{2001} & \multirow[b]{2}{*}{ Resistance from ${ }^{\text {" }}$} \\
\hline & & & $R^{2 \mathrm{u}}$ & $\operatorname{Add}^{\mathrm{V}}$ & $R^{2}$ & Add & $R^{2}$ & Add & \\
\hline \multicolumn{10}{|l|}{ Joint analysis ${ }^{\mathrm{x}}$} \\
\hline $2 \mathrm{DL}$ & Xgwm349 & 14.58 & 6.5 & 0.35 & 6.5 & 0.39 & 9.6 & 0.55 & Fukuho \\
\hline $5 \mathrm{BL}$ & Xwmc415 & 15.01 & 6.4 & 0.72 & 6.9 & 0.82 & 12.7 & 0.73 & Oligo \\
\hline $7 \mathrm{BL}$ & Xwmc166 & 15.36 & 9.0 & 0.75 & 2.5 & 0.46 & 7.0 & 0.47 & Oligo \\
\hline \multicolumn{3}{|c|}{ Total $R^{2}$ by joint analysis } & 35.6 & & 31.4 & & 48.2 & & \\
\hline $7 \mathrm{DSC}^{\mathrm{z}}$ & Xwmc405.2 & - & - & - & 6.0 & 0.61 & 8.8 & 0.63 & Fukuho \\
\hline
\end{tabular}

s Marker nearest to the peak of likelihood ratio plot.

${ }^{t}$ Likelihood ratio (LR); thresholds equivalent to LOD $=2.5$ are 11.5 for single year and 15.9 for joint analysis.

u The percentage of phenotypic variation explained by each QTL.

${ }^{v}$ Additive effect.

${ }^{\mathrm{w}}$ Fukuho $=$ 'Fukuho-komugi'; Oligo = 'Oligoculm'.

${ }^{x}$ Three years $(1999,2000$, and 2001) of data from Toluca, Mexico was jointly analyzed.

y Data analyzed by single year. Common QTLs from joint analysis not included.

${ }^{\mathrm{z}} \mathrm{C}=$ the region near the centromere. 
differences in leaf rust severity, when the population was classified into four groups based on the genotypes of the two loci, Xgwm295.1 and Xwmc44, are shown in Table 5. The genotype of Xwmc44 did not affect leaf rust severity when the allele at Xgwm295.1 was 'Fukuho-komugi type'.

Three marker loci having relatively large effects on stripe rust severity and infection type (Table 4) were chosen to determine their combined effects. The DH lines were classified into eight groups each consisting of 5 to $15 \mathrm{DH}$ lines (Table 6). The mean severity and infection type in the presence of resistance alleles at one of the three marker loci were lower than those lines that had susceptibility alleles, although the differences were not always significant. The mean severity and infection type of the DH lines, which had resistant alleles for all of the three marker loci $(R / R / R)$ were $33.3 \%$ and 4.1 , respectively, whereas those for the susceptible $(\mathrm{S} / \mathrm{S} / \mathrm{S}) \mathrm{DH}$ lines were $76.4 \%$ and 7.5 , respectively. This indicated that the level of resistance enhanced when resistance alleles were combined together in a single genotype.

\section{DISCUSSION}

Adult plant resistance genes with minor but additive effects on stripe and leaf rusts are common in wheat germ plasm $(12,22,43$, 51). Cultivars showing adequate resistance levels have several of these genes, which have small to intermediate effects in reducing rust severity and/or infection type (40). The distribution of stripe rust severity and infection type (Fig. 1) in our study confirms the quantitative nature of the effects of loci conditioning resistance to stripe rust. Only linked/pleiotropic genes Lr34/Yr18, Lr46/Yr29, and $S r 2 / L r 27 / Y r 30$ have gene symbols $(18,37,40)$.

QTL analyses of stripe rust severity at the adult plant stage have revealed that different cultivars contain different resistance genes $(2,4,5,40,42)$. Among the 11 QTLs for stripe rust severity detected by joint or single-environment analysis in our study, three QTLs (QTL-3BS, QTL-7DS, and QTL-2DS) were the same as those in previous studies. QTL-3BS and QTL-7DS are thought to be located in the same regions as QTLs detected in the International Triticeae Mapping Initiative (ITMI) mapping population, developed by crossing a hexaploid synthetic wheat with 'Opata 85' (42). These QTLs are considered to be due to the effects of genes $\mathrm{Yr} 30$ and $\mathrm{Yr} 18$, respectively. QTL-2DS was located in the same region as one of the QTLs detected by Bariana et al. (2). Plant heading and maturity could influence field evaluations of rust infections, i.e., late plants may display less disease severity due to later flag leaf emergence. The photoperiod insensitive gene Ppd-Dl located on chromosome 2DS (49) may be responsible for the detection of QTL-2DS, being as one QTL for maturity was detected in the same region in this population, which is highly variable for days to heading and maturity (unpublished data). The location of QTL-2DL for stripe rust infection type and severity was 40 to $50 \mathrm{cM}$ distal to that found by Boukhatem et al. (5) for stripe rust infection type and area

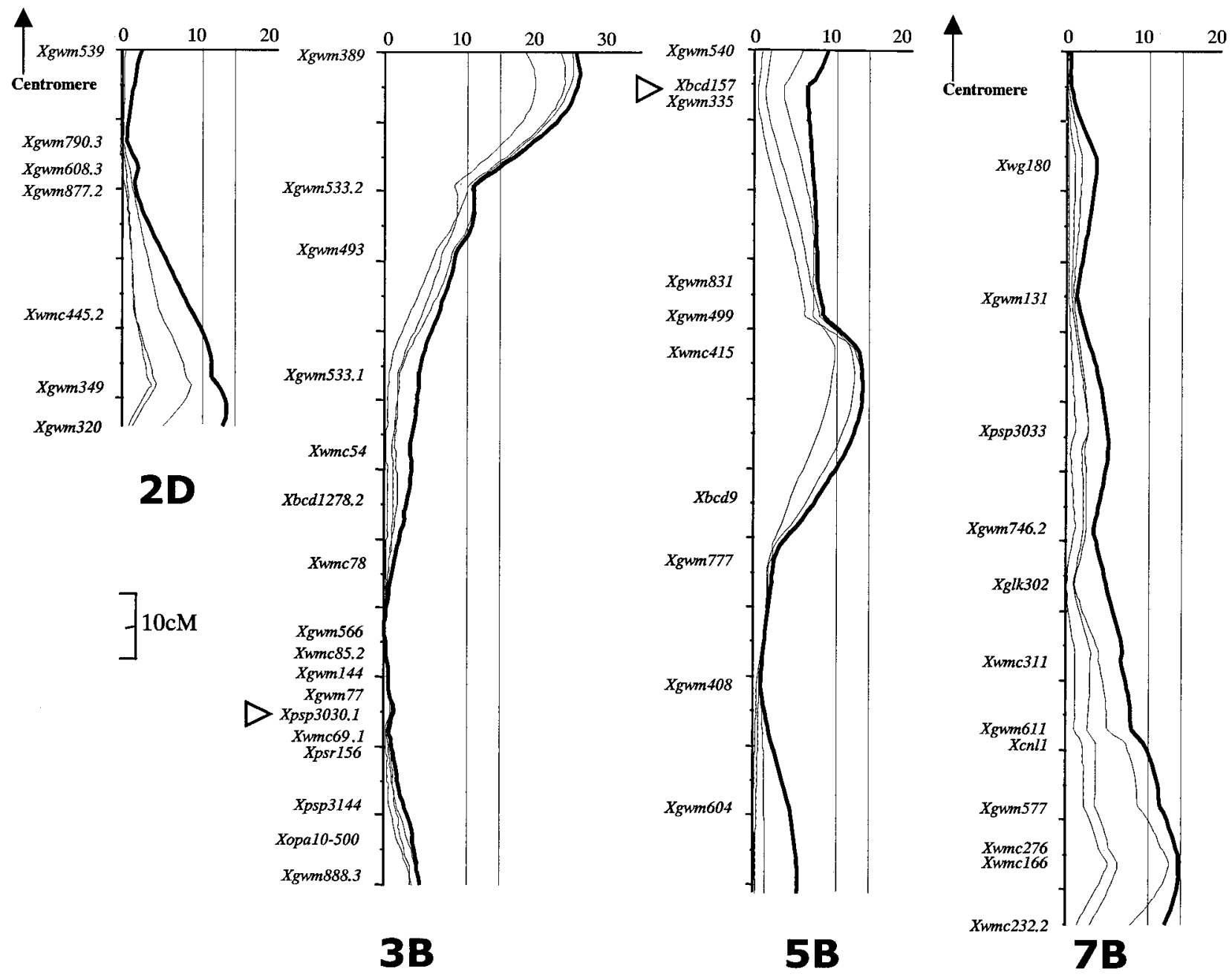

Fig. 4. Likelihood ratio (LR) contours obtained by composite interval mapping for four quantitative trait loci mapped on chromosomes 2DL, 3BS, 5BL, and 7BL that reduce stripe rust infection type in 'Fukuho-komugi' $\times$ 'Oligoculm' doubled haploid population evaluated for 3 years in field trials. Bold contours indicate LR by joint analysis with 3 years data. LR thresholds, equivalent to LOD $=2.5$, are 11.5 for single year and 15.9 for joint analysis. Short arms of the chromosomes are toward the top and the open arrow indicates centromere. 
under disease progress curves (AUDPC), indicating that these QTLs could be different.

Boukhatem et al. (5) analyzed stripe rust infection type at the adult plant stage and detected five QTLs. Two were located in the same region as QTL-3DS and QTL-7DS for stripe rust severity in a study by Singh et al. (42) using the same population. Boukhatem et al. (5) demonstrated high correlation between infection type and AUDPC in a different population. Four QTLs (QTL-2DL, QTL3BS, QTL-4DL, and QTL-5BL detected by joint or single-year/ environment analysis) were common to severity and infection type in our study (Table 4). This association was also indicated by a highly significant $(P<0.01)$ correlation coefficient $(r)$ of 0.79 between stripe rust severity and infection type. QTL-7DSC for stripe rust infection type was located in the same region as a QTL on 7DS for severity by Bariana et al. (2). The flanking locus, Xwmc405.2, was common to both. In our study, no distinct QTL for stripe rust severity was identified in this region, probably due to the large effect of QTL-7DS, which is approximately $30 \mathrm{cM}$ away from Xwmc405.2. Correlations between severity and infection type in stripe rust may be partly due to the systemic manner of stripe rust growth in leaf tissue and therefore, low disease severity is often associated with reduction in infection type (40). Association between stripe rust severity and infection type at QTL-7DS and QTL-7DSC in the present population (Table 4) is likely to be due to the linkage between these QTLs.

The QTLs identified in our study as being associated with stripe rust severity had varying effects. Some showed more stability across different environments, while others were not very stable. For example, among the 11 QTLs detected for stripe rust severity, four were significant only in one or two environments (Table 2). Moreover, the effects of QTL-4BL and QTL-5BL were different when data were recorded on two dates in 1999 (27 July and 5 August), indicating that the effect of a gene may change as growth-stage changes. QTL-7DS for $\mathrm{Yr} 18$, also detected in another population (42), showed the largest and most stable effect.

One of the two QTLs for leaf rust severity identified in our study, QTL-7DS for Lr34, was located in the same region as in another study using the ITMI mapping population by Nelson et al. (23). Nelson et al. (23) and Singh et al. (42) identified RFLP locus, Xwg384 that was linked to the QTL for $L r 34 / Y r 18$. The position of this QTL for leaf rust was almost the same as that for stripe rust severity (2 $\mathrm{cM}$ distal). Because it was difficult to classify $\mathrm{DH}$ lines for $\mathrm{Ltn}$ in the present population (due to large variation in several agronomic traits), Ltn could not be mapped into a unique position. Xgwm295.1, the nearest marker locus to

TABLE 5. Genotypic effects of flanking marker loci for quantitative trait loci on 7DS and $1 \mathrm{BL}$ on leaf rust severity individually and when present in four possible combinations

\begin{tabular}{llrrr}
\hline Locus & Genotype $^{\mathrm{y}}$ & 2000 & 2001 & Mean \\
\hline Xgwm295.1 (7DS) & $\mathrm{F}$ & 12.6 & 10.9 & 11.9 \\
& $\mathrm{O}$ & 57.1 & 46.6 & 52.1 \\
Xwmc44 (1BL) & dif & -44.6 & -35.7 & -40.1 \\
& $\mathrm{~F}$ & 47.6 & 41.4 & 44.9 \\
& $\mathrm{O}$ & 23.2 & 16.8 & 19.5 \\
Xgwm295.1/Xwmc44 & dif & 24.4 & 24.6 & 25.5 \\
& $\mathrm{~F} / \mathrm{O}(\mathrm{R} / \mathrm{R})$ & 12.6 & 10.1 & $11.3 \mathrm{a}^{\mathrm{z}}$ \\
& $\mathrm{F} / \mathrm{F}(\mathrm{R} / \mathrm{S})$ & 11.6 & 12.5 & $12.5 \mathrm{a}$ \\
& $\mathrm{O} / \mathrm{O}(\mathrm{S} / \mathrm{R})$ & 32.8 & 25.6 & $30.2 \mathrm{~b}$ \\
& O/F (S/S) & 80.4 & 66.4 & $73.0 \mathrm{c}$ \\
Average & dif (F/O & -67.8 & -56.3 & -61.6 \\
\hline & versus O/F) & & & \\
& & 35.1 & 28.0 & 31.2 \\
\hline
\end{tabular}

${ }^{\mathrm{y}} \mathrm{F}=$ 'Fukuho-komugi', $\mathrm{O}=$ 'Oligoculm', and dif = genotypic difference between $\mathrm{F}$ and $\mathrm{O}$ genotypes. $\mathrm{F}$ and $\mathrm{O}$ are resistant (R) and susceptible (S) for Xgwm295.1, and S and R for Xwmc44, respectively.

${ }^{z}$ Different letter indicates significant difference at $P<0.05$.

TABLE 4. Genotypic effects of the identified marker loci closest to the quantitative trait loci (QTLs) on leaf rust severity, stripe rust severity, and infection type in each of the field trials

\begin{tabular}{|c|c|c|c|c|c|c|c|c|c|c|c|c|c|}
\hline \multirow[b]{3}{*}{$\begin{array}{l}\text { Marker } \\
\text { locus }\end{array}$} & \multirow[b]{3}{*}{$\begin{array}{l}\text { Chromo- } \\
\text { some }^{\mathrm{w}}\end{array}$} & \multirow[b]{3}{*}{$\begin{array}{l}\text { Identified } \\
\text { for }^{\mathrm{X}}\end{array}$} & \multirow[b]{3}{*}{$\begin{array}{l}\text { Resistance } \\
\text { from }^{\mathrm{y}}\end{array}$} & \multicolumn{10}{|c|}{ Genotypic effect $^{\mathrm{v}}$} \\
\hline & & & & \multicolumn{2}{|c|}{ Leaf rust } & \multicolumn{5}{|c|}{ Stripe rust severity } & \multicolumn{3}{|c|}{ Stripe rust infection type } \\
\hline & & & & 2000 & 2001 & Australia & $\begin{array}{l}1999 \\
\text { July }\end{array}$ & $\begin{array}{c}1999 \\
\text { August }\end{array}$ & 2000 & 2001 & 1999 & 2000 & 2001 \\
\hline Xwmc320 & 1BLC & YrS-01 & Fukuho & -6.4 & -6.7 & $-11.0^{+}$ & $-11.3^{* *}$ & $-12.0^{*}$ & $-11.5^{*}$ & $-15.0^{* * \mathrm{z}}$ & -0.8 & -0.7 & $-0.9^{*}$ \\
\hline Xwmc44 & 1BLD & Lr-J & Oligo & $24.4^{* * * z_{z}}$ & $24.6^{* * * \mathrm{z}}$ & $8.8^{+}$ & 5.5 & $11.4^{*}$ & $10.8^{+}$ & $9.0^{*}$ & $0.8^{+}$ & $0.8^{*}$ & $0.7^{*}$ \\
\hline$X g d m 93.1$ & $2 \mathrm{BL}$ & YrIT-99 & Oligo & 3.2 & 5.5 & -0.9 & 3.2 & 5.3 & 5.0 & -4.3 & $1.3^{* * * \mathrm{z}}$ & $0.5^{+}$ & 0.3 \\
\hline Xgwm261 & 2DS & YrS-99 & Oligo & 7.2 & 0.8 & $9.8^{+}$ & $8.8^{* \mathrm{z}}$ & $11.3^{* \mathrm{z}}$ & $9.8^{+}$ & $9.6^{+}$ & 0.5 & 0.4 & 0.2 \\
\hline Xgwm349 & $2 \mathrm{DL}$ & $\begin{array}{l}\text { YrS-99, } \\
\text { YrIT-J }\end{array}$ & Fukuho & 0.3 & -6.2 & $-14.3^{* *}$ & $-12.1^{* * *} \mathrm{z}$ & $-16.8^{* * * \mathrm{z}}$ & $-15.9^{* * * *}$ & $-8.6^{+}$ & $-1.2^{* * \mathrm{z}}$ & $-1.1^{* * \mathrm{z}}$ & $-1.1^{* * z}$ \\
\hline Xgwm389 & $3 \mathrm{BSD}$ & $\begin{array}{l}\text { YrS-J, } \\
\text { YrIT-J }\end{array}$ & Oligo & 10.0 & $11.7^{+}$ & $11.8^{* \mathrm{z}}$ & $6.4^{+z}$ & $9.8^{* \mathrm{z}}$ & $12.4^{* \mathrm{z}}$ & $3.2^{z}$ & $1.6^{* * * * \mathrm{z}}$ & $1.7^{* * * * z}$ & $1.7^{* * * \mathrm{z}_{\mathrm{Z}}}$ \\
\hline Xgwm538 & $4 \mathrm{BL}$ & YrS-J & Oligo & -0.6 & -0.2 & $3.6^{\mathrm{z}}$ & $10.8^{* * z_{z}}$ & $7.6^{\mathrm{z}}$ & $11.6^{* \mathrm{z}}$ & $13.7^{* *_{\mathrm{z}}}$ & 0.4 & 0.0 & 0.4 \\
\hline Xwmc399 & $4 \mathrm{DL}$ & $\begin{array}{l}\text { YrS-J, } \\
\text { YrIT-00 }\end{array}$ & Oligo & 4.1 & 0.1 & $15.9^{* * \mathrm{z}}$ & $9.7^{* z}$ & $13.2^{* * \mathrm{z}}$ & $14.1^{* * \mathrm{z}}$ & $9.4^{+z}$ & $0.8^{+}$ & $1.1^{* *_{\mathrm{z}}}$ & $0.7^{+}$ \\
\hline Xwmc415 & $5 \mathrm{BL}$ & $\begin{array}{l}\text { YrS-J, } \\
\text { YrIT-J }\end{array}$ & Oligo & 7.6 & 6.3 & $19.9^{* * *_{\mathrm{z}}}$ & $4.8^{\mathrm{z}}$ & $12.6^{* * \mathrm{Z}}$ & $11.9^{* \mathrm{z}}$ & $5.8^{\mathrm{z}}$ & $0.9^{*} \mathrm{z}$ & $0.9^{* \mathrm{z}}$ & $1.1^{* * * * \mathrm{z}}$ \\
\hline$X w m c 215$ & $5 \mathrm{DL}$ & $\begin{array}{l}\text { YrS- } \\
\text { 99July }\end{array}$ & Oligo & -6.6 & -0.3 & -5.9 & $5.4^{+z}$ & 3.8 & $9.8^{*}$ & $8.1^{+}$ & -0.3 & 0.2 & -0.2 \\
\hline Xgwm935.1 & $6 \mathrm{BSC}$ & YrS-J & Oligo & -3.6 & -1.6 & $14.2^{+z}$ & $4.6^{\mathrm{z}}$ & $8.3^{\mathrm{z}}$ & $13.2^{+z}$ & $3.8^{\mathrm{z}}$ & 0.5 & 0.6 & 0.3 \\
\hline Xgwm 935.3 & 7BS & YrS-J & Oligo & 6.7 & 4.0 & $14.0^{* \mathrm{z}}$ & $6.7^{\mathrm{z}}$ & $13.3^{* \mathrm{z}}$ & $11.8^{\mathrm{z}}$ & $13.0^{* \mathrm{z}}$ & 0.4 & 0.4 & 0.2 \\
\hline Xwmc166 & $7 \mathrm{BL}$ & YrIT-J & Oligo & 4.1 & -0.3 & -1.8 & $6.5^{+}$ & 8.9 & 8.0 & $10.2^{*}$ & $1.1^{* *} \mathrm{z}$ & $0.6^{\mathrm{z}}$ & $0.8^{* \mathrm{z}}$ \\
\hline Xgwm295.1 & 7DS & $\begin{array}{l}\text { Lr-J, } \\
\text { YrS-J }\end{array}$ & Fukuho & $-44.5^{* * *} \mathrm{z}$ & $-35.7^{* * * *} \mathrm{z}$ & $-22.0^{* * *} \mathrm{z}$ & $-13.4^{* * * z}$ & $-17.6^{* * * z}$ & $-17.6^{* * * z}$ & $-21.8^{* * *} \mathrm{z}$ & $-0.8^{*}$ & $-0.9^{*}$ & $-1.0^{* *}$ \\
\hline Xwmc405.2 & 7DSC & $\begin{array}{l}\text { YrIT-00, } \\
\text { YrIT01 }\end{array}$ & Fukuho & $-30.1^{* * *}$ & $-19.5^{* * *}$ & $-12.7^{*}$ & $-9.7^{* *}$ & $-14.1^{* * * *}$ & $-15.9^{* *}$ & $-14.4^{* *}$ & $0.6+$ & $-0.9^{* \mathrm{z}}$ & $-0.8^{* z}$ \\
\hline
\end{tabular}

${ }^{\mathrm{v}}$ Values indicate the mean difference in rust scores of lines. Positive and negative values mean resistance is associated with 'Oligoculm' and 'Fukuho-komugi' allele at the marker locus, respectively. Significant difference at each locus: ${ }^{+}, *, * *$, and $* * *$ indicate significance at $P=01,0.05,0.01$, and 0.001 , respectively, in chi-square test by Map Manager Statistical Program (17), using no cofactors.

${ }^{\mathrm{w}}$ Chomosomal region $\mathrm{C}$ and $\mathrm{D}=$ the region of centromere and distal region, respectively.

${ }^{\mathrm{x}} \mathrm{Lr}=$ leaf rust, $\mathrm{Yr}=$ stripe rust, $\mathrm{S}=$ severity, $\mathrm{IT}=$ infection type, $99=$ single year analysis for $1999,00=$ single year analysis for $2000,01=$ single year analysis for 2001 , and $\mathbf{J}=$ joint analysis.

y Fukuho = 'Fukuho-komugi'; Oligo = 'Oligoculm'.

${ }^{\mathrm{z}}$ Flanking QTL were significant by either joint or single year/environment analysis. 


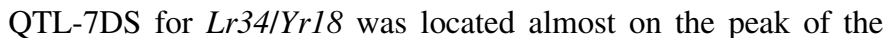
LR contour. Preliminary results using 36 CIMMYT spring wheat cultivars that have been characterized for the presence and absence of $\mathrm{Lr} 34 / \mathrm{Yr} 18$ indicated that in 30 cultivars we could use alleles of Xgwm295.1 to determine the presence and absence of Lr34/Yr18. This suggests that though not diagnostic, this marker has the potential to be used in marker-assisted selection. Xgwm295.1 is currently the closest known SSR marker for the gene complex Lr34/Yrl8.

The second QTL for leaf rust was located in the same chromosome region (1BL distal) as gene Lr46. Bariana et al. (2) detected a QTL for stripe rust severity in this region for Yr29. Gene Lr46 is very closely or completely linked to Yr29 (40). Although QTL analysis did not detect a significant effect on either stripe rust severity or infection type in this region, significant differences were found in at least two environments with a similar tendency for stripe rust (Table 4). The reduced effect of the QTL could be due to allelic differences at the $Y r 29$ locus, to the difference in genetic background, or to the segregation of several resistance genes in this cross (up to 11 QTLs for stripe rust severity; Table 2). In contrast, in 3BS distal region, where $\mathrm{Sr} 2 / \mathrm{Lr} 27 / \mathrm{Yr} 30$ genes are located $(23,42)$, no significant QTL for leaf rust severity could be detected although stripe rust infection type and severity were significantly reduced. Genotypic differences in leaf rust severity at the flanking locus (Xgwm389) were marginal but displayed the same tendency as stripe rust severity and infection type in both years. Genotypic effects of marker loci, Xwmc44 and Xgwm295.1, on leaf rust resistance QTLs are given in Table 5. The population was classified into four groups based on genotypes of these two marker loci. Since the position of Xwmc 44 was $5.6 \mathrm{cM}$ proximal to the LR peak for QTL-1BL (gene Lr46), a certain number of recombinants should be obtained when selecting for leaf rust based on the Xwmc44 genotype. The means of genotypes F/O and F/F (see Table 5) were 11.3 and $12.5 \%$, respectively, and there was no significant genotypic effect of Xwmc44 when locus Xgwm295.1 was of the 'Fukuho-komugi' type. This may imply that the two genes, Lr34 and Lr46, did not work additively. However, it must be mentioned that the $\mathrm{DH}$ lines were classified when the Lr34-carrying 'Fukoho-komugi' displayed only 5\% severity. Therefore, it is likely that significant interaction would have been observed had classification been done later in the season when disease has increased to a higher level (44).

Genotypic effects of marker loci were also evaluated for stripe rust severity and infection type. Although 11 and 7 QTLs were detected for stripe rust severity and infection type, respectively, only three marker loci with relatively large effects were chosen for this purpose. The effects of each marker loci were smaller as compared with leaf rust severity due to a greater number of genes involved and/or due to higher environmental effects. It seems that lines with higher level of resistance could be extracted based on

TABLE 6. Genotypic effects of flanking marker loci for quantitative trait loci on stripe rust severity and infection type individually and when present in eight possible combinations

\begin{tabular}{|c|c|c|c|}
\hline Locus & Genotype $^{y}$ & Resistance & Severity $(\%)^{\mathrm{z}}$ \\
\hline \multicolumn{4}{|l|}{ Stripe rust severity } \\
\hline \multirow[t]{2}{*}{ Xgwm295.1 (7DS) } & Fukuho-komugi & $\mathrm{R}$ & 44.1 \\
\hline & Oligoculm & $\mathrm{S}$ & 62.9 \\
\hline \multirow[t]{3}{*}{ Xwmc415 (5BL) } & Fukuho-komugi & $\mathrm{S}$ & 61.4 \\
\hline & Oligoculm & $\mathrm{R}$ & 46.1 \\
\hline & dif. & & 15.3 \\
\hline Xgwm389 (3BS) & Fukuho-komugi & $\mathrm{S}$ & 60.6 \\
\hline \multirow{7}{*}{ Xgwm295.1/Xwmc415/Xgwm389 } & $\mathrm{F} / \mathrm{O} / \mathrm{O}$ & $R / R / R$ & $33.3(13) \mathrm{a}$ \\
\hline & $\mathrm{F} / \mathrm{O} / \mathrm{F}$ & $\mathrm{R} / \mathrm{R} / \mathrm{S}$ & $49.4(5) \mathrm{ab}$ \\
\hline & $\mathrm{F} / \mathrm{F} / \mathrm{O}$ & $\mathrm{R} / \mathrm{S} / \mathrm{R}$ & $50.7(11) \mathrm{ab}$ \\
\hline & $\mathrm{F} / \mathrm{F} / \mathrm{F}$ & $\mathrm{R} / \mathrm{S} / \mathrm{S}$ & $54.3(7) \mathrm{b}$ \\
\hline & $\mathrm{O} / \mathrm{O} / \mathrm{O}$ & $\mathrm{S} / \mathrm{R} / \mathrm{R}$ & $54.5(6) \mathrm{b}$ \\
\hline & $\mathrm{O} / \mathrm{O} / \mathrm{F}$ & $\mathrm{S} / \mathrm{R} / \mathrm{S}$ & $58.4(8) b c$ \\
\hline & $\mathrm{O} / \mathrm{F} / \mathrm{O}$ & $\mathrm{S} / \mathrm{S} / \mathrm{R}$ & $64.9(9) \mathrm{bc}$ \\
\hline \multirow{2}{*}{ Xgwm389 (3BS) } & Oligoculm & $\mathrm{R}$ & 5.1 \\
\hline & dif & & 1.8 \\
\hline \multirow[t]{3}{*}{ Xwmc415 (5BL) } & Fukuho-komugi & $\mathrm{S}$ & 6.4 \\
\hline & Oligoculm & $\mathrm{R}$ & 5.2 \\
\hline & dif & & 1.2 \\
\hline \multirow[t]{3}{*}{ Xgwm349 (2DL) } & Fukuho-komugi & $\mathrm{R}$ & 5.3 \\
\hline & Oligoculm & $\mathrm{S}$ & 6.3 \\
\hline & dif & & -1.0 \\
\hline \multirow[t]{5}{*}{ Xgwm389/Xwmc415/Xgwm349 } & $\mathrm{O} / \mathrm{O} / \mathrm{F}$ & $\mathrm{R} / \mathrm{R} / \mathrm{R}$ & $4.1(13) \mathrm{a}$ \\
\hline & $\mathrm{O} / \mathrm{O} / \mathrm{O}$ & $\mathrm{R} / \mathrm{R} / \mathrm{S}$ & $5.1(9) a b$ \\
\hline & $\mathrm{O} / \mathrm{F} / \mathrm{F}$ & $\mathrm{R} / \mathrm{S} / \mathrm{R}$ & $5.5(8) b c$ \\
\hline & $\mathrm{O} / \mathrm{F} / \mathrm{O}$ & $\mathrm{R} / \mathrm{S} / \mathrm{S}$ & $5.7(15) b c$ \\
\hline & $\mathrm{F} / \mathrm{O} / \mathrm{F}$ & $\mathrm{S} / \mathrm{R} / \mathrm{R}$ & $5.3(5) \mathrm{ab}$ \\
\hline
\end{tabular}

${ }^{y} \mathrm{~F}=$ 'Fukuho-komugi', $\mathrm{O}=$ 'Oligoculm', and dif = genotypic difference between $\mathrm{F}$ and $\mathrm{O}$ genotypes.

${ }^{\mathrm{z}}$ Numbers in parenthesis indicate the number of doubled haploid (DH) lines classified into each genotypic group. Different letter following the means indicate significant difference at $P<0.05$. 
the genotypes of these marker loci. For example, the mean stripe rust severity and infection type of the DH lines carrying resistance alleles for all three marker loci $(\mathrm{R} / \mathrm{R} / \mathrm{R})$ were lowest $(33.3 \%$ mean severity and 4.1 for infection type) compared to the means of the lines which lacked the resistance alleles for the three marker loci (76.4\% severity and 7.5 for infection type) (Table 6).

Results of our study and those published earlier $(2,4,5,21,23,42)$ indicate that various QTLs are involved in adult plant resistance to stripe rust and leaf rust in wheat. The phenotypic effects of these genes are variable and may be influenced by the environment. However, some QTLs are detected repeatedly in the 1BL ( $r$ r46/Yr29), 3BS (Sr2/Lr27/Yr30), and 7DS (Lr34/Yrl8) regions and have shown greater effects $(\% R 2)$ than others. Therefore, loci in these chromosomal regions may be more important than others in conferring resistance to rust diseases in wheat. In fact, $L r 34 / Y r 18$ have been extensively utilized in achieving durable rust resistance in CIMMYT germ plasm derived wheat cultivars (40). As it has been observed that individual adult plant resistance genes are often insufficient to provide effective protection under high disease pressure, several of these genes must be present to achieve adequate protection. Although the marker locus, Xgwm295.1, seems to be very close to the genes, $\operatorname{Lr} 34 / Y r 18$, it is not a diagnostic marker for these genes. Distances between other flanking marker loci and the putative resistance genes detected in this study may not be close enough for marker-assisted selection. Therefore, it is necessary to further identify markers that are more tightly linked to the resistance genes. Successful tagging of these adult plant resistance genes with molecular markers should help not only to identify their presence in wheat cultivars but also to pyramid the most desirable gene combinations in new cultivars. Identifying markers associated with adult plant resistance genes could also provide the basis for saturating these important chromosomal regions with more markers, thereby facilitating fine mapping of the regions and cloning of these useful genes, which have shown durability.

\section{ACKNOWLEDGMENTS}

We thank J. Crossa, CIMMYT, and C. Jiang, Monsanto, for their valuable comments on statistical and QTL analysis. The first author is grateful to C. R. Wellings, University of Sydney for the valuable suggestions on the field evaluation for stripe rust in Australia. We also thank A. McNab, CIMMYT for her editorial review. The present study was a collaborative JIRCAS/CIMMYT effort supported by both organizations.

\section{LITERATURE CITED}

1. Ban, T., Suenaga, K., Niwata, E., and Kuroda, S. 1996. Screening of RAPD markers associated with pre-harvest sprouting resistance in wheat 1995. Pages 151-156 in: Seventh Int. Symp. Pre-Harvest Sprouting in Cereals. K. Noda and D. J. Mares, eds. Center for Academic Societies Japan, Osaka, Japan.

2. Bariana, H. S., Hayden, M. J., Ahmed, N. U., Bell, J. A., Sharp, P. J., and McIntosh, R. A. 2001. Mapping of durable adult plant and seedling resistances to stripe rust and stem rust diseases in wheat. Aust. J. Agric. Res. 52:1247-1255.

3. Bjarko, M. E., and Line, R. F. 1988. Heritability and number of genes controlling leaf rust resistance in four cultivars of wheat. Phytopathology 78:457-461.

4. Börner, A., Röder, M. S., Unger, O., and Meinel, A. 2000. The detection and molecular mapping of a major gene for non-specific adult-plant disease resistance against stripe rust (Puccinia striiformis) in wheat. Theor. Appl. Genet. 100:1095-1099.

5. Boukhatem, N., Baret, P. V., Mingeot, D., and Jacquemin, J. M. 2002. Quantitative trait loci for resistance against yellow rust in two wheat-derived recombinant inbred line populations. Theor. Appl. Genet. 104:111118.

6. Caldwell, R. M. 1968. Breeding for general and/or specific plant disease resistance. Pages 263-272 in: Proc. 3rd Int. Wheat Genetics Symp., K. W. Finlay and K. W. Shepherd, eds. Australian Academy of Science, Canberra, Australia.

7. Don, R. H., Cox, P. T., Wainwright, B. J., Baker, K., and Mattick, J. S.
1991. 'Touchdown' PCR to circumvent spurious priming during gene amplification. Nucleic Acids Res. 19:4008.

8. Dyck, P. L. 1987. The association of a gene for leaf rust resistance with the chromosome 7D suppressor of stem rust resistance in common wheat. Genome 29:467-469.

9. Dyck, P. L. 1991. Genetics of adult-plant leaf rust resistance in 'Chinese Spring' and 'Sturdy' wheats. Crop Sci. 31:309-311.

10. Hoisington, D., Khairallah, M., and Gonzalez-de-Leon, D. 1994. Laboratory protocols: CIMMYT Appl. Mol. Genet. Lab. 2nd ed. CIMMYT, Mexico, D.F., Mexico.

11. Jiang, C., and Zeng, Z. B. 1995. Multiple-trait analysis of genetic mapping for quantitative trait loci. Genetics 140:1111-1127.

12. Johnson, R. 1988. Durable resistance to yellow (stripe) rust in wheat and its implications in plant breeding. Pages 63-75 in: Breeding strategies for resistance to the rusts of wheat, N. W. Simmonds and S. Rajaram, eds. CIMMYT, Mexico D.F., Mexico.

13. Knott, D. R. 1988. Using polygenic resistance to breed for stem rust resistance in wheat. Pages 39-47 in: Breeding Strategies for Resistance to the Rusts of Wheat. N. W. Simmonds and S. Rajaram, eds. CIMMYT, Mexico D.F., Mexico.

14. Lander, E. S., Green, P., Abrahamson, J., Barlow, A., Daly, M. J., Lincoln, S. E., and Newburg, L. 1987. MAPMAKER: An interactive computer package for constructing primary genetic linkage maps of experimental and natural populations. Genomics 1:174-181

15. Ma, Z. Q., Röder, M., and Sorrells, M. E. 1996. Frequencies and sequence characteristics of di-, tri-, and tetra-nucleotide microsatellites in wheat. Genome 39:123-130.

16. Ma, H., and Singh, R. P. 1996. Contribution of adult plant resistance gene $\operatorname{Yr} 18$ in protecting wheat from yellow rust. Plant Dis. 80:66-69.

17. Manly, K. F., Cudmore, R. H., Jr., and Meer, J. M. 2001. Map Manager QTX, cross-platform software for genetic mapping. Mamm. Genome 12:930-932.

18. McIntoch, R. A. 1992. Close genetic linkage of genes conferring adultplant resistance to leaf rust and stripe rust in wheat. Plant Pathol. 41:523527.

19. McIntosh, R. A., Wellings, C. R., and Park, R. F. 1995. Wheat Rusts: An Atlas of Resistance Genes. CSIRO Australia, Melbourne, Australia, and Kluwer Academic Publ. Dordrecht, the Netherlands.

20. McNeal, F. H., Konzak, C. F., Smith, E. P., Tate, W. S., and Russell, T. S. 1971. A uniform system for recording and processing cereal research data. Pages 34-121 in: U.S. Dep. Agric. Agric. Res. Ser. Bull.

21. Messamer, M. M., Seyfarth, R., Keller, M., Schachermayr, G., Winzeler, M., Zanetti, S., Feuillet, C., and Keller, B. 2000. Genetic analysis of durable leaf rust resistance in winter wheat. Theor. Appl. Genet. 100:419-431.

22. Milus, E. A., and Line, R. F. 1986. Gene action for inheritance of durable, high-temperature, adult plant resistance to stripe rust in wheat. Phytopathology 76:435-441.

23. Nelson, J. C., Singh, R. P., Autrique, J. E., and Sorrells, M. E. 1997. Mapping genes conferring and suppressing leaf rust resistance in wheat. Crop Sci. 37:1928-1935.

24. Nelson, J. C., Sorrels, M. E., van Deynze, A. E., Lu, Y. H., Atkinson, M., Bernard, M., Leroy, P., Faris, J. D., and Anderson, J. A. 1995. Molecular Mapping of wheat: Major genes and rearrangements in homoeologous groups 4, 5, and 7. Genetics 141:721-731.

25. Parlevliet, J. E. 1975. Partial resistance of barley to leaf rust, Puccinia hordei. I. Effect of cultivar and development stage on latent period. Euphytica 24:21-27.

26. Peng, J. H., Fahima, T., Röder, M. S., Li, Y. C., Dahan, A., Grama, A., Ronin, Y. I., Korol, A. B., and Nevo, E. 1999. Microsatellite tagging of the stripe-rust resistance gene $\mathrm{YrH} 52$ derived from wild emmer wheat, Triticum dicoccoides, and suggestive negative crossover interference on chromosome 1B. Theor. Appl. Genet. 98:862-872.

27. Pestsova, E., Ganal, M. W., and Röder, M. S. 2000. Isolation and mapping of microsatellite markers specific for the D genome of bread wheat. Genome 43:689-697.

28. Peterson, R. F., Campbell, A. B., and Hannah, A. E. 1948. A diagrammatic scale for estimating rust severity on leaves and stems of cereals. Can. J. Res. Sect. C Bot. Sci. 26:496-500.

29. Raupp, W. J., Sukhwinder-Singh, Brown-Guedira, G. L., and Gill, B. S. 2001. Cytogenetic and molecular mapping of the leaf rust resistance gene Lr39 in wheat. Theor. Appl. Genet. 102:347-352.

30. Ribaut. J.-M., Jiang, C., Gonzalez-de-Leon, D., Edmeades, G. O., and Hoisington, D. A. 1997. Identification of quantitative trait loci under drought conditions in tropical maize. 2. Yield components and markerassisted selection strategies. Theor. Appl. Genet. 94:887-896.

31. Robert, O., Abelard, C., and Dedryver, F. 1999. Identification of molecular markers for the detection of the yellow rust resistance gene Yr17 in wheat. Mol. Breed. 5:167-175.

32. Röder, M. S., Korzun, V., Wendehake, K., Plaschke, J., Tixier, M. H., 
Leroy, P., and Ganal, M. W. 1998. A microsatellite map of wheat. Genetics 149:2007-2023.

33. Sanguinetti, C. J., Neto, E. D., and Simpson, A. J. G. 1994. Rapid silver staining and recovery of PCR products separated on polyacrylamide gels. Biotechniques 17:915-919.

34. Schachermyr, G., Siedler, H., Gale, M. D., Winzeler, H., Winzeler, M., and Keller, B. 1994. Identification and localization of molecular markers linked to the $\operatorname{Lr} 9$ leaf rust resistance gene of wheat. Theor. Appl. Genet. 88:110-115.

35. Singh, R. P. 1991. Pathogenicity variations of Puccinia recondita f. sp. tritici in wheat-growing areas of Mexico during 1988 and 1989. Plant Dis. 75:790-794.

36. Singh, R. P. 1992. Association between gene Lr34 for leaf rust resistance and leaf tip necrosis in wheat. Crop Sci. 32:874-878.

37. Singh, R. P. 1992. Genetic association of leaf rust resistance gene Lr34 with adult plant resistance to stripe rust in bread wheat. Phytopathology 82:835-838.

38. Singh, R. P., and Gupta, A. K. 1992. Expression of wheat leaf rust resistance gene Lr34 in seedlings and adult plants. Plant Dis. 76:489491.

39. Singh, R. P., and Huerta-Espino, J. 1997. Effect of leaf rust resistance gene Lr34 on grain yield and agronomic traits of spring wheat. Crop Sci. 37:390-395.

40. Singh, R. P., Huerta-Espino, J., and William, M. 2001. Slow rusting genes based resistance to leaf and yellow rusts in wheat: Genetics and breeding at CIMMYT. Pages 103-108 in: Proc. 10th Assembly of the Wheat Breeding Soc. of Australia, Mildura, Australia. Wheat Breeding Society of Australia Inc., Australia.

41. Singh, R. P., Mujeeb-Kazi, A., and Huerta-Espino, J. 1998. Lr46: A gene conferring slow-rusting resistance to leaf rust in wheat. Phytopathology
88:890-894.

42. Singh, R. P., Nelson, J. C., and Sorrells, M. E. 2000. Mapping Yr28 and other genes for resistance to stripe rust in wheat. Crop Sci. 40:11481155.

43. Singh, R. P., and Rajaram, S. 1991. Resistance to Puccinia recondita f. sp. tritici in 50 Mexican bread wheat cultivars. Crop Sci. 31:1472-1479.

44. Singh, R. P., and Rajaram, S. 1992. Genetics of adult-plant resistance to leaf rust in 'Frontana' and three CIMMYT wheats. Genome 35:24-31.

45. Song, Q. J., Fickus, E. W., and Cregan, P. B. 2002. Characterization of trinucleotide SSR motifs in wheat. Theor. Appl. Genet. 104:286-293.

46. Stephenson, P., Bryan, G., Kirby, J., Collins, A., Devos, K., Busso, C., and Gale, M. 1998. Fifty new microsatellite loci for the wheat genetic map. Theor. Appl. Genet. 97:946-949.

47. Suenaga, K., and Nakajima, K. 1993. Segregation of genetic markers among wheat doubled haploid lines derived from wheat $\mathrm{x}$ maize crosses. Euphytica 65:145-152.

48. Wellings. C. R., and McIntosh, R. A. 1990. Puccinia striiformis f. sp. tritici in Australasia: Pathogenic changes during the first 10 years. Plant Pathol. 39:316-325.

49. Worland, A. J., Korzun, V., Röder, M. S., Ganal, M. W., and Law, C. N. 1998. Genetic analysis of the dwarfing gene Rht8 in wheat. Part II. The distribution and adaptive significance of allelic variants at the Rht 8 locus of wheat as revealed by microsatellite screening. Theor. Appl. Genet. 96:1110-1120.

50. Zeng, Z. B. 1994. Precision mapping of quantitative trait loci. Genetics 136:1457-1468.

51. Zhang, Z. J., Yang, G. H., Li, G. H., Jin, S. L., and Yang, X. B. 2001. Transgresssive segregation, heritability, and number of genes controlling durable resistance to stripe rust in one Chinese and two Italian wheat cultivars. Phytopathology 91:680-686. 